\title{
Collaborating on Scholarship: Best Practices for Team Research Projects
}

\author{
Abstract \\ Collaborating on scholarship has the potential to provide many advantages, including benefiting \\ from others' expertise, reinforcing accountability, and providing motivation. However, working \\ with others is tricky_consider compatible work habits, receptivity to criticism, and commitment \\ to fulfill responsibilities. Decisions to be made include where to publish, in what order authors’ \\ names will appear, and how the manuscripts will be written. Who will coordinate? Who will \\ write what? Who will revise? Also, consider how to address problems - missed deadlines, less- \\ than-stellar quality, how to say "no" in the future, and more.
}

Keywords: Collaboration; authorship; publishing; presentations 


\section{Introduction}

Planning and organization are essential for a successful collaborative scholarship project. Although collaborators seldom discuss these elements in their publications or presentations, they are nevertheless an important part of the research process. Planning and organization are crucial because they provide a sound framework for a project. Once decisions are made and acted on, the collaborators can focus on research and writing rather than spending their time on damage control caused by poor planning. This article discusses the prevalence, benefits, and costs of collaboration, followed by strategies for planning all aspects of a collaborative research project. These aspects include selecting collaborators, agreeing on venues for presentations and publications, agreeing on authorship credits, and identifying roles, responsibilities, and expectations. Other aspects include creating a timeline, maintaining communication, using technology, addressing problems, and managing post-project issues.

\section{Prevalence of Collaboration}

Collaboration in library and information science (LIS) scholarship is a widespread practice, as documented in a variety of research studies. A series of studies examined the percentage of articles co-authored by U.S. academic librarians in a sample of LIS journals. Percentages were 45 in 1993 through 1997 (Weller, Hurd, and Wiberley 1999); 41.09 in 1998 through 2002 (Wiberley, Hurd, and Weller 2006), and 51.04 in 2003 through 2012 (Blecic et al. 2017). Other studies have analyzed the incidence of co-authored articles appearing in a particular journal over time. For example, the percentage of articles with co-authors in College \& Research Libraries ranged from 4.35 percent in 1939 through 1944 (Cline 1982) to 45.9 percent in 1985 through 1988 (Metz 1989) and then to 59.5 percent in 1989 through 1994 (Terry 1996). 
Collaboration on conference papers also has increased. For example, Fennewald (2007) investigated papers presented at Association for College and Research Libraries conferences from 1978 through 2005. He found that the incidence of papers with two co-authors increased from twenty-four percent in 1978 through 1984 to thirty-two percent in 2001 through 2005. Furthermore, the incidence of papers with three to seven co-authors increased from seven percent in 1978 through 1984 to twenty-one percent in 2001 through 2005.

\section{Benefits and Costs of Collaboration}

Collaborating on scholarship has the potential to provide many practical benefits. Collaborators can provide expertise and ideas to improve a project (Hart 2000). Authors can learn new skills and habits from their collaborators (Silvia 2015). Collaboration may allow authors to be more productive because they are dividing the work with others (Fox and Faver 1982). A significant relationship between collaboration and research outputs was documented in a study by Hoffmann, Berg, and Koufogiannakis (2017). Some research has found a higher acceptance rate for co-authored articles than for solo-authored articles, as noted in a study of submissions to College \& Research Libraries (Hernon, Smith, and Croxen 1993).

Collaborative projects also may result in social benefits. Collaboration provides a way to increase one’s professional network (Jacobs, McIntosh, and O’Sullivan 2018). It may reduce a sense of isolation sometimes felt by researchers who usually work alone (Fox and Faver 1984). Collaborative projects may offer opportunities to mentor others in scholarship (Hart 2000). Collaborators may hold each other accountable and provide motivation to complete projects (Jacobs, McIntosh, and O’Sullivan 2018).

The costs of collaborative projects should be considered as well as the benefits. Fox and Faver (1984) have identified process costs and outcome costs in collaboration. Process costs include 
the time and energy required not only for negotiating the details of a project, but also for cultivating and sustaining interpersonal relationships with collaborators. Outcome costs may be incurred if a collaborator contributes poor quality work or slows down the project. Such outcome costs may be avoided in many cases by carefully selecting collaborators and agreeing on clearly defined expectations.

\section{Choosing Collaborators}

Choosing team members is one of the most crucial steps of a collaborative project. Consider a variety of intellectual, personal, and structural factors when assessing the qualifications of potential team members (Fox and Faver 1982). Intellectual factors include expertise, theoretical orientation, and interests. Personal factors comprise work habits, time management skills, compatible personalities, receptivity to constructive criticism, and willingness to follow through on commitments. Structural factors include the size of the team. Cassidy and Colmenares (2014) recommend that the team be composed of a maximum of four individuals. Another structural factor is the balance of power in a team, which is influenced by the status or ranks of the participants (Ocampo and Gayles 2019). For example, the balance of power in a team made up of two entry-level librarians would differ greatly from a team composed of an entry-level librarian and a library dean.

Another factor to consider is potential team members' experience in scholarship. Read articles they have written to judge their experience in publication. View slideshows and recordings of presentations they have made to evaluate their experience in presentations.

Once the team is complete, the process of planning the project begins. Although the team may be led by a principal investigator or coordinator, all team members should participate in planning the project in a democratic process (Cassidy and Colmenares 2014). Group harmony is more 
likely if all team members know their voices are being heard. The team should record its plans and decisions in shared documents. Some teams accomplish this by writing formal agreements that are signed by all participants (Jacobs, McIntosh, and O’Sullivan 2018).

\section{Educating Inexperienced Collaborators}

If the team includes inexperienced collaborators, other members of the team should educate them so they will understand what is expected of them. If the project is a journal article, a team member should explain the process of writing, revising, submitting an article for review, and responding to reviewers' comments. The team member also should provide examples of wellwritten articles. More information about this topic may be found in Belcher (2019) and Silvia (2015). If the project is a conference presentation, the team member should explain the process of submitting a proposal as well as creating, revising, and delivering a presentation. The team member also should provide examples of presentations with well-designed slides. Further guidance may be found in Feldman and Silvia (2010) and Hilyer (2008).

\section{Monitoring Opportunities}

Collaborators should monitor opportunities for publications and presentations. One of the most comprehensive sources is A Library Writer's Blog (Seeman 2020). Other sources include libraryrelated electronic discussion lists which may include notices of publication and presentation opportunities. Many directories of library-related electronic discussion lists are available, including those maintained by the American Library Association (2020) and Loyola University Chicago Libraries (2020). In addition, journal websites may include calls for papers. Likewise, conference websites may include calls for proposals. Many library-related conference websites may be accessed through directories such as those maintained by Georgia College (2020) and Thull and Dworaczek (2020). 
The team may consider publication and presentation opportunities outside of LIS. Many academic librarians publish and make presentations in venues related to higher education or their subject specialties. Librarians also collaborate with authors outside their field to publish in nonLIS scholarly journals, as noted by Borrego, Ardanuy, and Urbano (2018). They found that articles authored by librarians collaborating with faculty in other fields fell into four categories: “a) papers on topics related to LIS; b) higher education and information literacy; c) systematic reviews and meta-analysis; and d) papers co-authored by librarians and researchers in the scholars' fields of expertise” (Borrego, Ardanuy, and Urbano 2018, 665). Librarians who collaborate with faculty on research projects participate in a wide range of activities, but most often in critically reviewing and revising the research paper (Borrego and Pinfield 2020).

\section{Agreeing on the Venue}

When selecting a venue for a publication or a presentation, collaborators should consider how various types of research outputs are evaluated in their library. Not all academic libraries agree on how they define acceptable forms of publications and presentations. Research by Sassen and Wahl (2014) indicated that books and peer-reviewed articles are valued more than other types of publications. Additionally, conference presentations are valued more than panel discussions or posters. However, the team does not have to choose only one option to report on a research project. A team may decide to create a poster first, followed by a conference presentation, and later a peer-reviewed journal article, all on the same topic.

If the team decides to write a journal article, one of the first steps is to choose a journal. Of course, the research topic must fit within the scope of the journal. The team should identify journals in which articles about the research topic have been published and thus derive a list of potential journals for their project. Other considerations are whether the journal is peer-reviewed, 
whether it is open access, its acceptance rate, and its journal impact factor. Ulrichsweb (2020) and Cabell's Directory of Publishing Opportunities in Educational Technology and Library Science (2020) are helpful in answering these questions. More information about choosing a journal may be found in Belcher (2019).

Collaborators must weigh several factors when deciding on a venue for a conference presentation. One of the most important factors is how well the research topic fits within the scope of the conference. Another factor concerns how the authors' library may evaluate the conference based on its geographic scope. An academic library may judge a conference with an international or national scope more favorably than a conference with a regional, state, or local scope. A third factor concerns the funding available for conference registration and any travel expenses.

\section{Agreeing on Authorship}

The team should agree on authorship credits and the order of authors' names. This should be done early in the collaboration process to avoid tension and disagreements.

First, the team should agree on which individuals will be designated as authors of their work. The Publication Manual of the American Psychological Association defines authorship as “substantial professional contributions" including "formulating the problem or hypothesis, structuring the experimental design, organizing and conducting the statistical analysis, interpreting the results, or writing a major portion of the paper” (American Psychological Association 2010).

Second, the team should agree on the order of the authors' names. Matkin and Riggar (1991) suggest several approaches. The traditional approach is to list authors' names either by the 
amount of work they contributed, the importance of their contributions, or their assigned responsibilities. If authorship is equally shared, the authors' names may be listed alphabetically. Alternatively, they may be listed in a different order accompanied by a note indicating that authorship is equally shared. If the same writers share authorship equally on more than one paper, they may agree to vary the order of the authors' names in the byline of each paper. When publishing in a field other than LIS, be aware that the order in which authors' names are listed varies by discipline (Silvia 2015).

\section{Identifying Roles, Responsibilities, and Expectations}

The team should agree on roles, responsibilities, and expectations at the beginning of the project. First, designate a project coordinator and agree on the responsibilities for that role. Next, reach consensus about how the project will be created. Some tasks may be shared by everyone, while others may be divided and assigned to individuals (Fox and Faver 1982). For example, everyone may participate in writing the outline of an article, while writing the article may be divided into sections and assigned to individuals. The task of revision also may involve varying levels of participation. For example, all co-authors may decide to share the task of revising the content of the paper. However, they may select one individual with strong editing skills to revise the entire text to make the style consistent. When deciding how to divide responsibilities, the team should consider the nature of the work, the expertise of team members, their preferences, and time constraints (Fox and Faver 1982).

Another decision concerns submission responsibilities. With a conference presentation, determine who will submit the proposal to the conference planners and keep up with correspondence about it. With a journal article, decide who will submit the article to the journal portal or editor, and who will be the corresponding author. 
The team also should agree on the operational definitions of the topics to be covered in their research and the finite scope of the research questions. Failing to take these steps at the beginning of the project could cause a significant waste of time and effort, leading to damaged relationships with collaborators.

\section{Note Important Dates and Create a Timeline}

Any collaborative scholarship project will benefit greatly from the creation of a timeline with all important dates included. Some may be imposed by an external group, such as the deadline for a poster proposal submission, and some may be created by the group, such as a due date for a preliminary draft. Do not forget to include deadlines for things such as speaker contracts, photographs and bios, or submission of handouts. Additionally, there may be post-acceptance or post-presentation deadlines, such as revisions or uploads to conference websites. The team may decide to schedule a practice run-through for a presentation or build in time to revise the article.

An agreed-upon and documented timeline is very important because it ensures that everyone on the team knows what is due when. One way to ensure everyone is aware of deadlines is to create placeholders on team member's calendars (using a meeting request for after hours, for example); team members must "accept" the fake appointment, thus committing to the deadline. It may also be prudent to schedule "check-in meetings" at regular intervals to keep the project on people’s minds. Having a check-in every three weeks seems reasonable and not intrusive; the project may come to a standstill otherwise. These serve as reminders, help keep people on pace, and can easily be moved or cancelled. It is important to keep the project on people's minds and keep everyone connected (Campbell, Ellis, and Adebonojo 2012; Crase and Rosato 1992).

A timeline should be realistic given that everyone has a full-time job. All should expect delays. Be flexible, and build in time for unforeseen things, such as a lengthy wait for approval from an 
Institutional Review Board. The team should renegotiate deadlines but be aware that the project may stall if things are continuously rescheduled (Cassidy and Colmenares 2014).

\section{Maintaining Communication and Using Technology}

It is helpful to assign one person the responsibility of coordination and keeping things on track. This is not necessarily always the first author and was playfully referred to in one presentation as "the executioner" (Hodges and Wright 2015). Things this person can do are to schedule check-in meetings, write and distribute minutes and action items, maintain the shared documents, remind people about the timeline, send status updates, and reinforce accountability regarding deadlines and deliverables.

Collaboration is enhanced through technology. One easy way to maintain centralized and consistent communication is to use tools most people already have access to. Office 365 has several applications that will improve the collaboration experience. Create a "Group" and use it so everyone has quick access to team emails; documents can be stored in the group's SharePoint, and meetings can be done in Microsoft Teams. Other collaboration tools include Google Workspace, Confluence, Basecamp, and Trello. Instead of getting confused with multiple drafts shared by email, a shared document space will keep all involved writing and revising on the same versions of documents (Silvia 2015).

Before writing, the group should agree on the software to be used for writing text or creating a presentation or poster. For a research paper, this will probably be Microsoft Word, but someone else in the group may have a different preference (such as LaTeX). Another consideration is the formatting of bibliographic references. Although the format may be prescribed by the chosen publication or presentation outlet, there are multiple ways to insert references, and using more than one can become problematic. Perhaps one collaborator enters them individually, and 
another is using the Word "Footnotes" feature to enter things automatically. This lack of uniformity will cause confusion in the revision stage. Citation management software, such as RefWorks, may help.

\section{Addressing Problems}

When working with others, there are expectations for behavior (Bahr and Zemon 2000).

Problems can usually be avoided if one chooses team members wisely, but sometimes issues will arise. Unfortunately, not all collaborations are fruitful; there may be someone who does not uphold their end of the bargain or produces low quality work (Ocampo and Gayles 2019). Sometimes, it may even be oneself who is not able to deliver. Collaborators need to acknowledge that not every project will be smooth. It is important to know how to handle problems, to decide what the group will tolerate, and how to “escape” (Jacobs, McIntosh, and O’Sullivan 2018).

If a collaborator misses deadlines, have an initial talk with them about the timeline and make necessary adjustments. If they repeatedly miss deadlines, or stop participating in the project altogether, initiate a frank discussion about the situation. Sometimes, collaborators may need to alter assignments and expectations. In other cases, a collaborator may decide that it is best to leave the project. If there are over two collaborators, converse with the rest of the group about how to proceed, and how many chances to give this person.

Sometimes a collaborator may produce work that is below the expected quality. They may have gotten the tone of the project wrong, perhaps more or less scholarly than originally agreed upon, or not quite right for the selected journal or conference. In this case, remind them of the original discussions, pointing to the notes taken at the beginning of the project about how the work would be written. Ask for a revision. Be prepared to revise their work. At this point, perhaps the preproject decisions should be renegotiated. Maybe the collaborator in question should be "lower" 
in the author list, or in extreme circumstances, they may not be in the follow-up team that is going to do the next phase of research or create a new output from the same research.

Similarly, a collaborator might take their work in a completely different topical direction than the team planned. At the beginning, the team made sure that the scope and purpose of the project was understood by all. When someone veers off course, redirect them to the original research question(s). When a collaborator continues to add new ideas, utilize a "parking lot" to table conversation on ideas that are off-topic or less relevant to the original purpose, and suggest including those ideas in an "Ideas for Future Research” section of the project.

The above considerations concern a partner who is not meeting expectations. However, sometimes, it is actually oneself who is unable to deliver. If one cannot meet deadlines or is creating sub-standard work, be humble and honest early. Talk to the team and be prepared to back out of the project. On the other hand, if colleagues provide concerns about one's performance, it is best to be gracious and accept their feedback. Being responsive and correcting the work will make it easier for the entire team to work together on a future project.

Collaborators may have different views on the "primacy of work," or the level of importance it holds in their work lives (Fox and Faver 1982). If the project stalls or team members decide to stop work, all should discuss what work remains their own, and what can be done with it. If one collaborator has done a substantial literature review, for example, they may be able to publish it without the team as co-authors. Perhaps a collaborator may decide not to keep certain individuals in their "research network" (Kennedy, Brancolini, and Kennedy 2020). If approached in the future, be able to say 'no' when asked about other projects. One may not have time, or perhaps instead of research, one may focus on service. Conceivably what they propose is not on one's research agenda, or one does not aspire to get into "that level" of research. Being direct with a 
former collaborator about why a new project is not feasible is optimal; use the following suggestions about a post-project debrief to address why the collaboration may have broken down.

\section{Post-Project Considerations and Debrief}

Success might mean finishing the writing. Success might mean getting accepted. It might mean delivering the presentation and handling Q\&A masterfully. Whichever form of success, there are multiple considerations. Institutions might require an update to an online $\mathrm{CV}$ which requires one person to enter information for all collaborators, or perhaps the institution has a repository where the group can save a version of the paper, presentation, or poster, or even the data collected for research.

Conversely, the team may have succeeded in writing a paper, but was not so successful in getting acceptance for journal publication. Rather than stopping work, the group can then discuss alternative publication venues, and who will be responsible for revisions (Lamothe 2012). Hopefully, retractions of any part of an accepted paper will not be an issue, but collaborators should acknowledge that this can happen, and someone should be assigned to handle it. On a happier note, success deserves reward. How will the team promote accomplishments? After adding it to CVs, consider who on the team can use social media and network connections to get the word out—more views would theoretically increase chances for citation.

After a project is done, it is prudent to undertake a post-project debrief, both as a collaborative team, and alone. Think about what worked well in the overall scheme of things. What was not as smooth? And what could be changed next time? Reflecting on this will not only enhance the next project, but it allows for decisions regarding future team members (Austin and Baldwin 1991). Although some research has shown that we frequently find collaborators serendipitously (Tran 
and Chan 2020), writers are likely to work together again when the original collaboration succeeded.

\section{Conclusion}

Collaborating with others on research projects can spark creativity, help with motivation, and expand a research network. Co-authoring may increase chances for publication, and potentially expand one's CV (and the literature of the profession) more quickly. See the appendix for a basic checklist delineating the main considerations.

Attention to roles, deadlines, scope, authorship, and problems is essential for successful collaboration. Hopefully, the recommendations in this paper can add to the lack of LIS literature on how to work together. 


\section{References}

American Library Association. 2020. ALA Electronic Discussion Lists. Accessed 20 September 2020. https://lists.ala.org/sympa/lists.

American Psychological Association. 2010. Publication Manual of the American Psychological Association. 6th ed. Washington, DC: American Psychological Association.

Austin, Ann E., and Roger Baldwin. 1991. Faculty Collaboration: Enhancing the Quality of Scholarship and Teaching. Washington, DC: ASHE-ERIC Higher Education.

Bahr, Alice Harrison, and Mickey Zemon. 2000. “Collaborative Authorship in the Journal Literature: Perspectives for Academic Libraries Who Wish to Publish.” College \& Research Libraries 61 (5): 410-419. doi:10.5860/crl.61.5.410.

Belcher, Wendy Laura. 2019. Writing Your Journal Article in Twelve Weeks: A Guide to Academic Publishing Success. 2nd ed. Chicago: The University of Chicago Press.

Blecic, Deborah D., Stephen E. Wiberley Jr., Sandra L. De Groote, John Cullars, Mary Shultz, and Vivian Chan. 2017. "Publication Patterns of U.S. Academic Librarians and Libraries from 2003 to 2012.” College \& Research Libraries 78 (4): 442-458. doi:10.5860/crl.78.4.442.

Borrego, Ángel, Jordi Ardanuy, and Cristóbal Urbano. 2018. “Librarians as Research Partners: Their Contribution to the Scholarly Endeavour Beyond Library and Information Science.” Journal of Academic Librarianship 44 (5): 663-670. doi:10.1016/j.acalib.2018.07.012. 
Borrego, Ángel, and Stephen Pinfield. 2020. "Librarians Publishing in Partnership with Other Researchers: Roles, Motivations, Benefits, and Challenges.” portal: Libraries \& the Academy 20 (4): 655-675.

Cabell's Directory of Publishing Opportunities in Educational Technology and Library Science. 2020. Beaumont, Texas: Cabell Publishing Co.

Campbell, Kathy, Mark Ellis, and Leslie Adebonojo. 2012. "Developing a writing group for librarians: The Benefits of Successful Collaboration.” Library Management 33 (1/2): 1421.

Cassidy, Erin Dorris, and Angela Colmenares. 2014. "Making tenure: A model for collaborative publishing." Paper presented at the American Library Association Annual Conference, Las Vegas, NV, June 28. https://www.slideserve.com/thanh/making-tenure-a-model-forcollaborative-publishing.

Cline, Gloria S. 1982. “College \& Research Libraries: Its First Forty Years.” College \& Research Libraries 43 (3): 208-232. doi:10.5860/crl_43_03_208.

Crase, Darrell, and Frank D. Rosato. 1992. "Single Versus Multiple Authorship in Professional Journals.” Journal of Physical Education, Recreation \& Dance 63 (7): 28-31.

Feldman, David B., and Paul J. Silvia. 2010. Public Speaking for Psychologists: A Lighthearted Guide to Research Presentations, Job Talks, and Other Opportunities to Embarrass Yourself. Washington, DC: American Psychological Association.

Fennewald, Joseph. 2007. “The ACRL Conferences: A Profile of its Presenters.” College \& Research Libraries 68 (2): 107-118. doi:10.5860/crl.68.2.107. 
Fox, Mary Frank, and Catherine A. Faver. 1982. "Process of Collaboration in Scholarly Research.” Scholarly Publishing 13: 327-339.

Fox, Mary Frank, and Catherine A. Faver. 1984. “Independence and Cooperation in Research: The Motivations and Costs of Collaboration.” Journal of Higher Education 55 (3): 34759.

Georgia College. 2020. Library Professional Development: Conferences, accessed September 21, 2020. https://libguides.gcsu.edu/c.php?g=292986\&p=1951024.

Hart, Richard L. 2000. “Collaborative Publication by University Librarians: An Exploratory Study.” Journal of Academic Librarianship 26 (2): 94-99. doi:10.1016/S00991333(99)00145-7.

Hernon, Peter, Allen Smith, and Mary Bailey Croxen. 1993. "Publication in College \& Research Libraries: Accepted, Rejected and Published Papers, 1980-1991.” College \& Research Libraries 54 (4): 303-321. doi:10.5860/crl_54_04_303.

Hilyer, Lee Andrew. 2008. Presentations for Librarians: A Complete Guide to Creating Effective, Learner-Centred Presentations. Oxford: Chandos.

Hodges, Tracy, and Katherine Wright. 2015. Beyond Just Team Building: Sailing Through Effective Collaboration. Paper presented at the Textbook and Academic Authoring Association Conference, Las Vegas, Nevada, June 19-20.

Hoffmann, Kristin, Selinda Berg, and Denise Koufogiannakis. 2017. "Understanding Factors that Encourage Research Productivity for Academic Librarians.” Evidence Based Library \& Information Practice 12 (4): 102-128. doi:10.18438/B8G66F. 
Jacobs, Courtney, Marcia McIntosh, and Kevin M. O'Sullivan. 2018. “Collaborative Authorship as Peer Mentorship.” College \& Research Libraries 79 (5): 606-610. doi:10.5860/crl.79.5.606.

Kennedy, Marie, Kristine Brancolini, and David Kennedy. 2020. “An Exploratory Study of Accomplished Librarian-Researchers.” Evidence Based Library and Information Practice 15 (1): 179-217.

Lamothe, Alain. 2012. “The Importance of Encouraging Librarians to Publish in Peer-Reviewed Publications.” Journal of Scholarly Publishing 43 (2): 156-167.

Loyola University Chicago Libraries. 2020. Library Science: Current Awareness. Accessed September 21, 2020. https://libguides.luc.edu/c.php?g=484243\&p=3333462.

Matkin, Ralph E., and T. F. Riggar. 1991. Persist and Publish: Helpful Hints for Academic Writing and Publishing. Niwot, CO.: University Press of Colorado.

Metz, Paul. 1989. “A Statistical Profile of College \& Research Libraries.” College \& Research Libraries 50 (1): 42-47. doi:10.5860/crl_50_01_42.

Ocampo, Anthony, and Joy Gaston Gales. 2019. "Collaboration and Conflict in Academe.” Inside Higher Ed, May 3. https://www.insidehighered.com/advice/2019/05/03/adviceensuring-effective-scholarly-collaborations-opinion.

Sassen, Catherine, and Diane Wahl. 2014. "Fostering Research and Publication in Academic Libraries.” College \& Research Libraries 75 (4): 458-491. doi:10.5860/crl.75.4.458.

Seeman, Corey. 2020. A Library Writer’s Blog. Accessed September 21, 2020. http://librarywriting.blogspot.com. 
Silvia, Paul J. 2015. Write it Up: Practical Strategies for Writing and Publishing Journal Articles. Washington, DC: American Psychological Association.

Terry, James L. 1996. “Authorship in College \& Research Libraries Revisited: Gender, Institutional Affiliation, Collaboration.” College \& Research Libraries 57 (4): 377-383. doi:10.5860/crl_57_04_377.

Thull, James, and Marian Dworaczek. 2020. International Library Related Conferences. Accessed September 21, 2020. https://www.lib.montana.edu/ james/.

Tran, Ngoc-Yen, and Emily Chan. 2020. "Seeking and Finding Research Collaborators: An Exploratory Study of Librarian Motivations, Strategies, and Success Rates.” College \& Research Libraries 81 (7): 1095-1105. doi:10.5860/crl.81.7.1095.

Ulrichsweb. 2020. New Providence, N.J.: R.R. Bowker.

Weller, Ann C., Julie M. Hurd, and Stephen E. Wiberley, Jr. 1999. "Publication Patterns of U.S. Academic Librarians from 1993 to 1997.” College \& Research Libraries 60 (4): 352362. doi:10.5860/crl.60.4.352.

Wiberley, Stephen E., Jr., Julie M. Hurd, and Ann C. Weller. 2006. "Publication Patterns of U.S. Academic Librarians from 1998 to 2002.” College \& Research Libraries 67 (3): 205216. doi:10.5860/crl.67.3.205. 


\section{Appendix}

\section{Checklist for Successful Collaboration}

\begin{tabular}{|c|c|}
\hline $\begin{array}{l}\text { Choose collaborators carefully. } \\
\text { Consider expertise, work ethic, } \\
\text { communication skills, receptivity to } \\
\text { feedback, time management skills, and } \\
\text { compatible personalities. }\end{array}$ & $\begin{array}{l}\text { Note important dates and create a } \\
\text { timeline. } \\
\text { Include deadlines for drafts, internal } \\
\text { peer-review, finished products, and } \\
\text { external requirements such as speaker } \\
\text { contracts, photographs, biographies, and } \\
\text { handouts. }\end{array}$ \\
\hline $\begin{array}{l}\text { Educate inexperienced collaborators. } \\
\text { Explain the steps in the project. Give } \\
\text { them examples of well-written articles or } \\
\text { well-designed slide shows. }\end{array}$ & $\begin{array}{l}\text { Maintain regular communication. } \\
\text { Schedule check-in meetings. Write and } \\
\text { distribute meeting minutes and action } \\
\text { items. Maintain shared documents. Send } \\
\text { status updates. Reinforce accountability. }\end{array}$ \\
\hline $\begin{array}{l}\text { Monitor opportunities. } \\
\text { Keep up with blogs, listservs and } \\
\text { conference websites listing calls for } \\
\text { papers or presentations. }\end{array}$ & $\begin{array}{l}\text { Use technology to facilitate } \\
\text { collaboration. } \\
\text { Create an electronic group to share team } \\
\text { emails and documents. Agree on the } \\
\text { software to use in creating documents } \\
\text { and managing citations. }\end{array}$ \\
\hline $\begin{array}{l}\text { Agree on the venue. } \\
\text { How well does the project fit the scope } \\
\text { of a potential venue? Is the journal peer- } \\
\text { reviewed? Is the journal open access? } \\
\text { What is the reputation of the conference? }\end{array}$ & $\begin{array}{l}\text { Address problems. } \\
\text { Be frank. Give constructive feedback. } \\
\text { Cut losses when necessary. }\end{array}$ \\
\hline $\begin{array}{l}\text { Agree on authorship. } \\
\text { Should the authors' names be listed } \\
\text { alphabetically, in the order of the amount } \\
\text { of work contributed, or in some other } \\
\text { order? }\end{array}$ & $\begin{array}{l}\text { Handle post-project responsibilities. } \\
\text { If the project was rejected by a journal or } \\
\text { conference, discuss alternative venues. } \\
\text { Use social media to promote the project's } \\
\text { success. Add the project to the } \\
\text { institution's institutional repository. } \\
\text { Update CVs. }\end{array}$ \\
\hline $\begin{array}{l}\text { Identify roles, responsibilities, and } \\
\text { expectations. }\end{array}$ & Hold a post-project debriefing. \\
\hline
\end{tabular}




\begin{tabular}{|l|l|l|}
\hline $\begin{array}{l}\text { Who will coordinate the project? Will } \\
\text { one person write the entire draft, or will } \\
\text { sections be divided among team } \\
\text { members? How will the draft be revised? }\end{array}$ & $\begin{array}{l}\text { What worked well? What did not go } \\
\text { Are the operational definitions and } \\
\text { research questions clearly delineated? }\end{array}$ &
\end{tabular}

